\title{
Effect of sitagliptin on depression in male wistar rats
}

\author{
Vidya M. Mahalmani ${ }^{1 *}$, Anil P. Hogade ${ }^{1}$, Sanjay K. Mishra ${ }^{2,3}$
}

\author{
${ }^{1}$ Department of Pharmacology, Jawaharlal Nehru Medical College, Belagavi, Karnataka, India \\ ${ }^{2}$ Scientist Grade II, KAHER's Dr. Prabhakar Kore Basic Science Research Center, Belagavi, Karnataka, India. \\ ${ }^{3}$ Associate Professor, College of Pharmacy, Belagavi, Karnataka, India.
}

Received: 26 March 2019

Revised: 12 December 2019

Accepted: 13 December 2019

\section{*Correspondence:}

Dr. Vidya M. Mahalmani,

Email: vidyapattanshetti88@gmail.com

Copyright: $\odot$ the author(s), publisher and licensee Medip Academy. This is an open-access article distributed under the terms of the Creative Commons Attribution Non-Commercial License, which permits unrestricted non-commercial use, distribution, and reproduction in any medium, provided the original work is properly cited.

\begin{abstract}
Background: Growing evidence supports relationship between depression and inflammation. The hypothesis of involvement of inflammatory pathways in depression is supported by the findings of increased levels of proinflammatory cytokines. So, we decided to evaluate the effect of sitagliptin on depression using forced swim test (FST) and possible effects of sitagliptin on serum oxidative stress markers and cytokine gene expression in rat hippocampus.

Methods: FST model was used to evaluate antidepressant effect in male wistar rats. Rats in group I (control group) were given normal saline, group II (standard group) were given fluoxetine, group III and IV (test groups) were given sitagliptin $5 \mathrm{mg} / \mathrm{kg}$ and sitagliptin $9 \mathrm{mg} / \mathrm{kg}$ respectively. All the drugs in all groups were given per orally. At the end, animals were sacrificed and blood was collected. Hippocampus of rat brain was dissected out. Serum oxidative stress markers and hippocampal pro inflammatory cytokine gene expression analysis was carried out.

Results: Sitagliptin $5 \mathrm{mg} / \mathrm{kg}$ and $9 \mathrm{mg} / \mathrm{kg}$ showed reduction in depressive symptoms and hippocampal cytokine gene expression in comparison to control. In case of serum oxidative stress markers, there was statistically significant reduction in nitric oxide levels with stagliptin $9 \mathrm{mg} / \mathrm{kg}$. Although there was a decrease in the levels of catalase and increase in the levels of glutathione with standard and test groups, the results were not statistically significant.

Conclusions: The present study showed significant antidepressant effect activity of standard and test groups. Hence, further research should be carried out to substantiate above results.
\end{abstract}

Keywords: Depression, Inflammation, Cytokine gene expression, Oxidative stress marker

\section{INTRODUCTION}

Mental disorders have always been complicated to define and diagnose, more difficult to treat successfully, thus a huge burden to the entire community. Depression is a psychiatric disorder characterized by the presence of cognitive, affective, psychomotor and neurovegetative symptoms, which pervades all aspects of life and impairs individuals' family and personal relationships, work adjustment and general health. ${ }^{1}$
In terms of public health significance, depression is the third leading cause of global disease burden, accounting for $4.3 \%$ of total disability-adjusted life years. If current trends continue, it will become the leading cause of disease burden by the year $2030 .^{2}$ Lifetime incidence of major depressive disorder is about $10-25 \%$ in women and $5-12 \%$ in men. Recurrence occurs in 50-60\% of those experiencing a single depressive episode. ${ }^{3}$

Till now the selective serotonin reuptake inhibitors, tricyclic antidepressants and newer atypical 
antidepressants have been the pharmacological options available for treating patients with depression. About one third of these patients do not respond primarily to antidepressant therapy. Those who do respond will progressively become resistant to treatment or show relapse. ${ }^{3}$ Also, pathophysiology of the disorder still remains obscure. For decades, researchers have been focussing mainly on monoamines. Several data are available in literature regarding the alternatives to serotonin (5HT), norepinephrine and dopamine. Despite extensive research done on these neurotransmitter systems, data available is inconclusive and monoamine hypothesis does not seem sufficient to explain the entire picture of depression. ${ }^{4}$ Recent advancement in neurobiological research provides increasing evidence that inflammatory and neurodegenerative pathways would play a relevant role in the development of depression. The hypothesis of the involvement of inflammatory pathways in depression is consistently supported by the findings of increased levels of several inflammatory markers including pro inflammatory cytokines such as interleukin $\beta$ (IL $\beta$ ), interleukin 6 (IL6), interferon $\gamma$ (IFN $\gamma$ ) and tumour necrosis factor $\alpha$ (TNF $\alpha)$. These findings have led to the novel idea of using cytokines as biomarkers of depression and the potential utility of developing new antidepressants that oppose cytokine action. ${ }^{5}$

It is a well-established fact that type 2 diabetes mellitus is a chronic metabolic disorder characterised by insulin resistance and inflammatory state in the body. Various studies show that dipeptidyl peptidase 4 Inhibitors (DPP4), sitagliptin cause dose dependent inhibition of pro inflammatory cytokines TNF $\alpha$, INF $\gamma$ and various interleukins. ${ }^{5}$ However, there is a scarcity of studies regarding the effect of sitagliptin on depression. Hence, the present research is undertaken to explore the effects of sitagliptin on depression in male wistar rats.

\section{METHODS}

Adult male wistar rats weighing $175 \pm 25 \mathrm{~g}$ were obtained from the central animal house of J. N. Medical College, Belagavi. Total 24 animals were included in the study. They were divided into four groups with six animals in each group $(n=6)$. They were housed under standard laboratory conditions and acclimatized to $12-12 \mathrm{hr}$ light/dark cycle for 10 days prior to the day of experimentation. They were maintained on standard chow pellet and water ad libitum. The study was approved by the IAEC (Institutional Animal Ethics Committee) and CPCSEA guidelines were followed throughout the study. CPCSEA registration number: 627/02/a/CPCSEA.

\section{Dosage}

Test drug used was sitagliptin $5 \mathrm{mg} / \mathrm{kg}$ and $9 \mathrm{mg} / \mathrm{kg}$. Standard drug used was fluoxetine $2.7 \mathrm{mg} / \mathrm{kg}$. Normal saline $0.1 \mathrm{ml} / \mathrm{kg}$ was used for control group. All drugs were administered through per oral route. Drugs used in the study were in tablet form and were procured from local pharmacy. Vehicle used to dissolve the drug was normal saline.

\section{Forced swim test}

The apparatus used for this test was a vertical plexiglass cylinder measuring $40 \mathrm{~cm}$ in height and $18 \mathrm{~cm}$ in diameter. The apparatus was filled with water upto $15 \mathrm{~cm}$ and the temperature was maintained at $25 \pm 2^{\circ} \mathrm{C}$. Forced swim comprised of two swim sessions. First session is called "pre-test" where adult male wistar rats weighing $175 \pm 25 \mathrm{~g}$ were subjected to swimming for 15 minutes. The immobility time was measured only when the rat ceased to struggle and remained floating motionless in the water making only those movements necessary to keep its head above the water. The rats were then removed, dried, warmed under 60 watt bulb. Later, test drug was administered and rats were returned back to their cages to provide with food and water. On the next day i.e. 24 hours later the rats were given next doses of drug orally; 4 hours and 1 hour prior to test respectively. Then they were subjected to forced swim test (FST) and the duration of immobility, climbing movement and active swimming (in seconds) was recorded for 6 minutes. ${ }^{6}$ After the experimental period, all animals were euthanized by cervical dislocation method (as per the guidelines of CPCSEA)

\section{Sample collection}

After euthanizing, $3 \mathrm{ml}$ of the truncal blood was collected and immediately sent for centrifugation to separate the serum that was stored at $-80^{\circ} \mathrm{C}$. This serum was used to measure oxidative markers [catalase, nitric oxide (NO), reduced glutathione (GSH)]. Then rat brain was dissected out. Hippocampus was removed and fixed in $10 \%$ neutral buffered formalin and embedded in paraffin blocks and was stored at $-80^{\circ} \mathrm{C}$. These brain tissues were used for neuroinflammatory gene expression (TNF $\alpha$, IL-1 $\beta$, IL-6).

\section{Biochemical assay and gene expression}

Estimation of oxidative stress markers

\section{Reduced GSH assay}

Sulfosalicylic [0.6\%] acid was added to plasma. The tubes were centrifuged at $8000 \mathrm{rpm}$ for 10 minutes at $4^{\circ} \mathrm{C}$. Supernatant obtained was mixed with $2 \mathrm{ml}$ of buffer. $0.1 \mathrm{ml}$ of freshly prepared 5, 5'- dithio-bis-2-nitrobenzoic acid was added and absorbance measured spectrophotometrically at $412 \mathrm{~nm}$. A standard curve was plotted using $10-100 \mu \mathrm{M}$ of reduced form of $\mathrm{GSH}^{7}$

\section{Estimation of $\mathrm{NO}$}

The NO production was assessed indirectly by measuring the nitrite levels in plasma determined by a calorimetric 
method based on the Griess reaction. Standard nitrite concentration in the range $0-100 \mu \mathrm{M}$ was prepared. Plasma samples were deproteinised by zinc sulphate and $\mathrm{NaOH}$, centrifuged and supernatant was used in the assay. Griess reagent (1\% sulphanilamide in 5\% phosphoric acid and $0.1 \%$ N-[1-Napthyl]ethylenediamine) was added to the supernatant incubated at room temperature for 15 minutes and absorbance was read at $540 \mathrm{~nm}$. Nitrite was quantified by using sodium nitrite as a standard curve. ${ }^{8}$

\section{Estimation of catalase}

$0.2 \mathrm{ml}$ of plasma sample was incubated in $1.0 \mathrm{ml}$ substrate $(65 \mu \mathrm{M}$ per $\mathrm{ml}$ hydrogen peroxide in $60 \mathrm{mmol} / \mathrm{l}$ sodium-potassium phosphate buffer; $\mathrm{pH} 7.0$ ) at $37^{\circ} \mathrm{C}$ for $60 \mathrm{~s}$. Sample catalase activity is linear up to $100 \mathrm{kU} / \mathrm{l}$. If the catalase activity exceeded $100 \mathrm{kU} / \mathrm{l}$, the samples were diluted with the phosphate buffer (2- to 10-fold) and the assay was repeated. One unit catalase decomposes $1 \mu \mathrm{M}$ of hydrogen peroxide/min under these conditions. The enzymatic reaction was terminated with $1.0 \mathrm{ml}$ of 32.4 $\mathrm{mmol} / \mathrm{l}$ ammonium molybdate [(NH4)6Mo7O24.4H2O] and the yellow complex of molybdate and hydrogen peroxide was measured at $405 \mathrm{~nm}$ on the spectrophotometer against the blank containing all the components except the enzyme and expressed in $\mathrm{kU} / \mathrm{l}$, where $\mathrm{k}$ is the first-order rate constant. ${ }^{9}$

\section{Gene expression}

Total RNA was prepared from isolated brain by using the triazole reagent, according to the manufacturer's instructions (GIBCO-BRL, Grand Island biological company, New York, USA). Reverse transcription was performed on equal amounts of total RNA by using random hexanucleotide primers to produce first-strand cDNA for each sample. The synthesized cDNA was used as a template for polymerase chain reaction (PCR) amplification. Real time PCR was performed by using step one real time PCR system (Applied Biosystem). The IL-6, IL-1 $\beta$ and TNF- $\alpha$. Synergy Brand.inc (SYBR) Green primers was used for real time RT-PCR analysis. PCR was carried out for 45 cycles using the following conditions: denaturation at $95^{\circ} \mathrm{C}$ for 45 seconds, annealing at $62.7^{\circ} \mathrm{C}$ for 30 seconds and elongation at $72^{\circ} \mathrm{C}$ for 15 seconds. Gene expression for IL- 6 , IL- $1 \beta$, TNF- $\alpha$ was studied. ${ }^{10}$

\section{Statistical analysis}

Data was expressed as Mean \pm SD. Data was analyzed by using one-way analysis of variance (ANOVA) followed by Bonferroni's multiple comparison test. ${ }^{11} \mathrm{p} \leq 0.05$ was considered to be statistically significant. Graph Pad Prism 6.0 software, a statistical analysis tool was utilized for all the analysis.

\section{RESULTS}

\section{Duration of immobility}

The mean duration of immobility in the control group was $79.25 \pm 16.66$ while in fluoxetine $2.7 \mathrm{mg} / \mathrm{kg}$ dose: $43.63 \pm 5.65$, sitagliptin $5 \mathrm{mg} / \mathrm{kg}$ dose: $57.88 \pm 10.13$ and sitagliptin $9 \mathrm{mg} / \mathrm{kg}$ dose: $51.88 \pm 9.40$. Duration of immobility was significantly decreased in Fluoxetine ( $\mathrm{p}<0.01)$, sitagliptin $9 \mathrm{mg} / \mathrm{kg}$ group when compared to that of control group. Sitagliptin $5 \mathrm{mg} / \mathrm{kg}(\mathrm{p}>0.05) \mathrm{did}$ not show significant results when compared to control group (Figure 1).

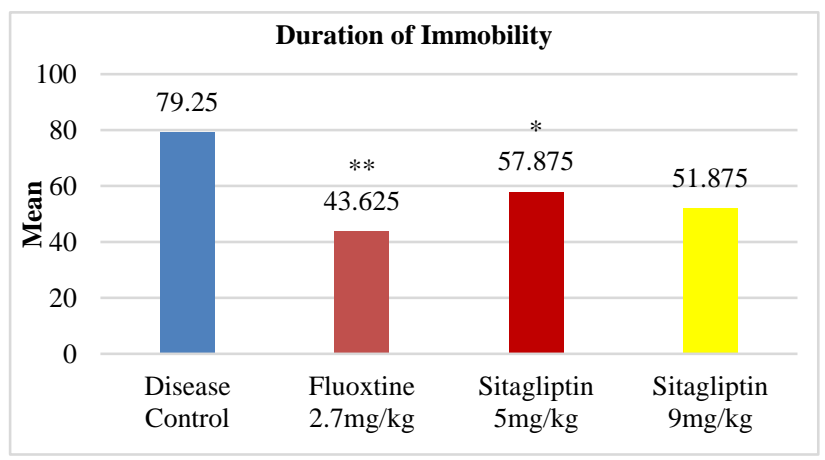

Figure 1: Effect of various treatments on duration of immobility (in seconds) in forced swim test.

Note: Data expressed as Mean \pm SD, ANOVA followed by Bonferroni's multiple comparison. $* \mathrm{p}>0.05, * * \mathrm{p}<0.01$ as compared to control group.

\section{Duration of climbing movement}

The mean duration of climbing movement in the control group was $20.13 \pm 1.80$ while in fluoxetine $2.7 \mathrm{mg} / \mathrm{kg}$ dose: $30.25 \pm 2.05$, sitagliptin $5 \mathrm{mg} / \mathrm{kg}$ dose: $21.00 \pm 2.00$, sitagliptin $9 \mathrm{mg} / \mathrm{kg}$ dose: $31.38 \pm 1.84$. Duration of climbing movement was significantly increased in fluoxetine, sitagliptin $9 \mathrm{mg} / \mathrm{kg}$ group $(\mathrm{p}<0.001)$ when compared to control group (Figure 2).

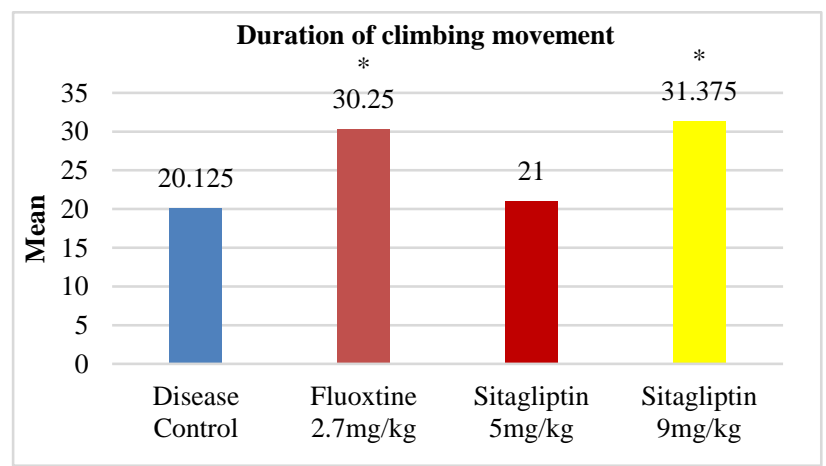

Figure 2: Effect of various treatments on duration of climbing movement (in seconds) in forced swim test. Note: Data expressed as Mean $\pm \mathrm{SD}$, ANOVA followed by Bonferroni's multiple comparison, ${ }^{*} \mathrm{p}<0.001$ as compared to control group. 


\section{Duration of active swimming}

The mean duration of active swimming in the control group was $27.25 \pm 2.31$ while in fluoxetine $2.7 \mathrm{mg} / \mathrm{kg}$ dose: $35.00 \pm 2.00$, sitagliptin $5 \mathrm{mg} / \mathrm{kg}$ dose: $26.75 \pm 2.81$, sitagliptin $9 \mathrm{mg} / \mathrm{kg}$ dose: $34.25 \pm 1.98$. Duration of active swimming was significantly increased in Fluoxetine, sitagliptin $9 \mathrm{mg} / \mathrm{kg}$ group $(\mathrm{p}<0.001)$ when compared to that of control group (Figure 3 ).

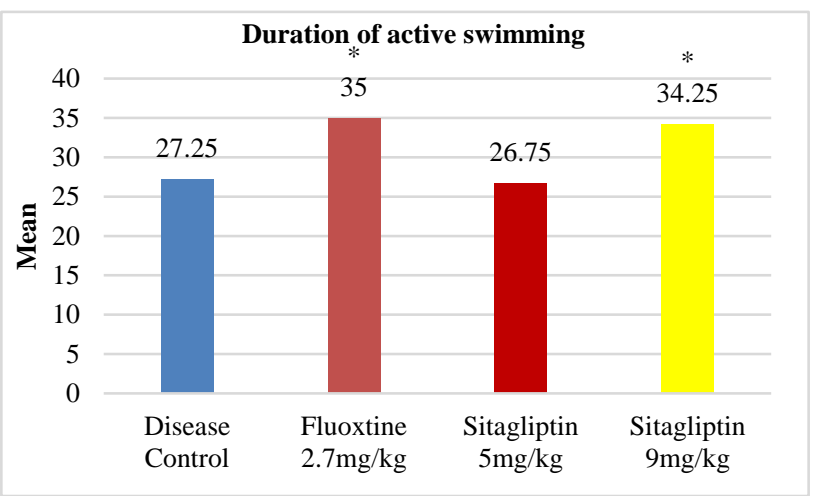

Figure 3: Effect of various treatments on duration of active swimming (in seconds) in forced swim test.

Note: Data expressed as Mean \pm SD, ANOVA followed by Bonferroni's multiple comparison, ${ }^{*} \mathrm{p}<0.001$ as compared to control group.

\section{Effect of various treatments on gene expression}

\section{Interleukin-1 $\beta$}

Sitagliptin $5 \mathrm{mg} / \mathrm{kg}$ and $9 \mathrm{mg} / \mathrm{kg}$ showed significant reduction in IL-1 $\beta$ levels compared to control group (Figure 4).

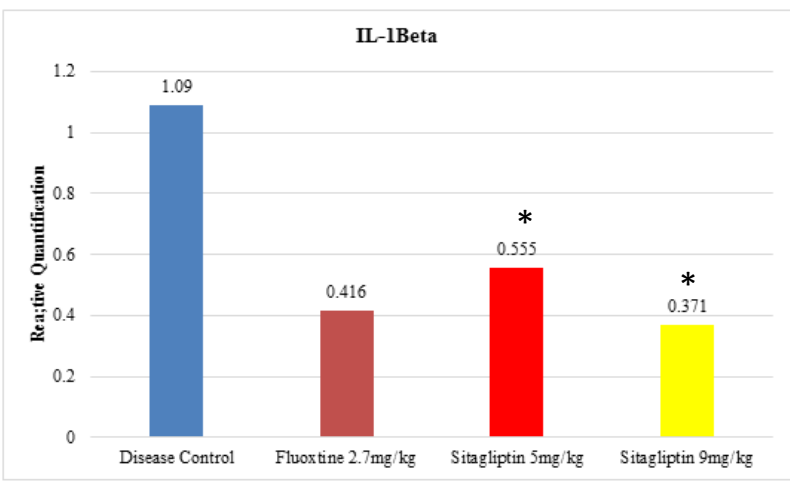

Figure 4: Effect of sitagliptin on interleukin $1 \beta$. Note: Data expressed as Mean \pm SD, ANOVA followed by Bonferroni's multiple comparison, $* \mathrm{p}<0.001$ as compared to control group.

\section{Interleukin 6}

Sitagliptin though showed a decrease in the levels of IL6 levels compared to control group, however the results were not statistically significant (Figure 5).

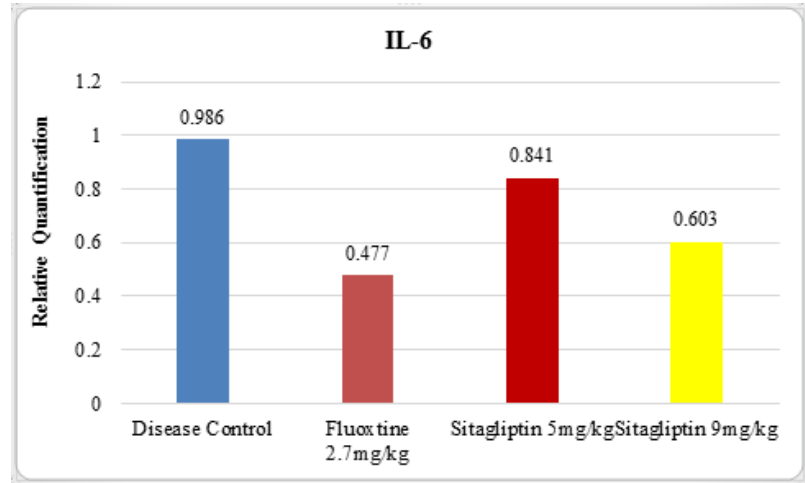

Figure 5: Effect of sitagliptin on interleukin 6.

Note: Data expressed as Mean \pm SD, ANOVA followed by Bonferroni's multiple comparison, ${ }^{*} \mathrm{p}<0.001$ as compared to control group.

\section{Tumour necrosis factor a}

Sitagliptin $9 \mathrm{mg} / \mathrm{kg}$ showed significant reduction in the levels of TNF $\alpha$ when compared to control group (Figure 6).

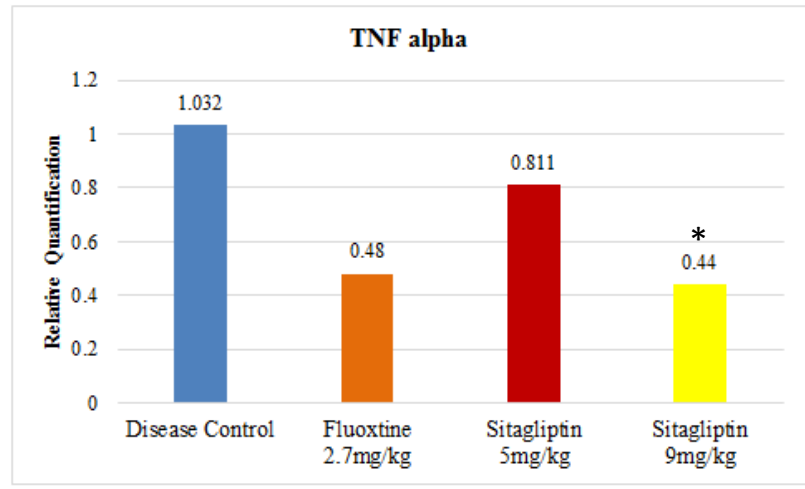

Figure 6: Effect of sitagliptin on tumour necrosis factor $\alpha$.

Note: Data expressed as Mean $\pm \mathrm{SD}$, ANOVA followed by Bonferroni's multiple comparison, ${ }^{*} \mathrm{p}<0.001$ as compared to control group.

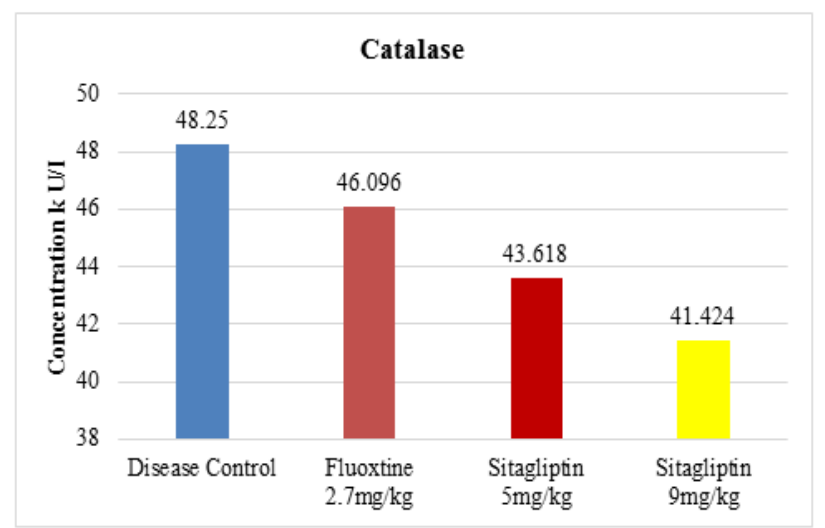

Figure 7: Effect of sitagliptin on catalase.

Note: Data expressed as Mean \pm SD, ANOVA followed by Bonferroni's multiple comparison. 


\section{Effect of various treatments on oxidative stress markers}

\section{Catalase}

Sitagliptin though showed a decrease in the levels of IL6 levels compared to control group, however the results were not statistically significant (Figure 7).

\section{Nitric oxide}

Sitagliptin $9 \mathrm{mg} / \mathrm{kg}$ showed significant reduction in the levels of nitric oxide (Figure 8).

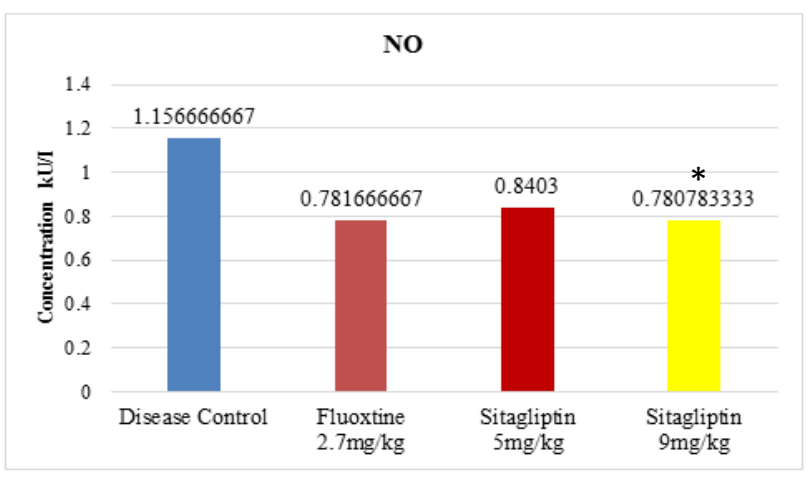

Figure 8: Effect of sitagliptin on nitric oxide.

Note: Data expressed as Mean \pm SD, ANOVA followed by Bonferroni's multiple comparison, ${ }^{*} \mathrm{p}<0.001$ as compared to control group.

\section{Reduced GSH}

Sitagliptin showed an increase in the levels of reduced glutathione compared to control group, however the results were not statistically significant (Figure 9).

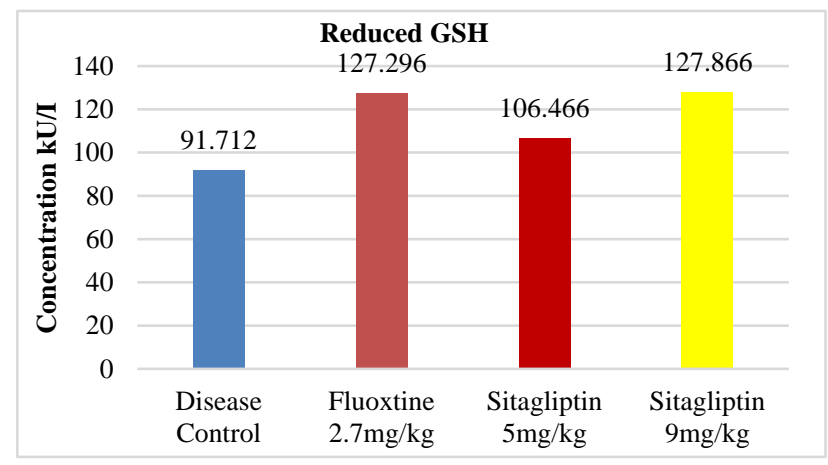

Figure 9: Effect of sitagliptin on reduced GSH.

Note: Data expressed as Mean $\pm \mathrm{SD}$, ANOVA followed by Bonferroni's multiple comparison.

\section{DISCUSSION}

The highest duration of immobility was noticed in control group whereas the highest duration of active swimmimg and climbing was observed in sitagliptin groups. Both the standard drug and test drug were found to be effective in comparison to control group. The results of standard and test drugs were almost comparable as there was no significant difference among them.

Sitagliptin is a dipeptidyl peptidase inhibitor. Kamble et al in his study proved that in FST model for depression, the duration of immobility with sitagliptin $(6 \mathrm{mg} / \mathrm{kg})$ was significantly reduced suggesting its antidepressant effect in comparison to control group. ${ }^{12}$ In a study by Marques et al sitagliptin $10 \mathrm{mg} / \mathrm{kg}$ was able to ameliorate nephropathy induced by diabetes in a T2DM animal model, the ZDF (fa/fa) rats, due to anti-inflammatory and antiapoptotic properties. ${ }^{13}$

In a study by El sahar et al depicted a marked antioxidant potential of sitagliptin as demonstrated by the reduction of the lipid peroxidation marker TBARS and the nitrosative stress indicator NOx, as well as replenishing the key cellular non-enzymatic antioxidant GSH. ${ }^{14}$ Sitagliptin 3 $\mathrm{mg} / \mathrm{kg}$ and $6 \mathrm{mg} / \mathrm{kg}$, reduced the duration of immobility in a dose-dependent manner but it was statistically significant $(\mathrm{p}<0.05)$ with the higher dose only. ${ }^{12}$

Our study showed that sitagliptin $9 \mathrm{mg} / \mathrm{kg}$ and vildagliptin $18 \mathrm{mg} / \mathrm{kg}$ significantly reduced the mean duration of immobility, increased the mean duration of active swimming, climbing movements compared to the control group. These results were also comparable with standard drug fluoxetine. Above results suggest that sitagliptin could alleviate depressive behaviour in male wistar rats.

Small gene expression studies $(\mathrm{N}<100)$ have shown an increased expression of IL- 6 and TNF- $\alpha$ in MDD. ${ }^{13.14}$ Meta-analyses of longitudinal studies suggest a causal pathway from inflammation to MDD. ${ }^{15,16}$ Numerous studies have reported increase in circulating proinflammatory cytokines, interleukin IL-1, IL-6, TNF $\alpha$ in depression. ${ }^{17}$ So we planned to perform a gene expression study to measure the levels of inflammatory markers IL1 $\beta$, IL6 and TNF $\alpha$. Sample taken for gene expression study was hippocampus of rat brain.

\section{Ill beta}

In our study sitagliptin $9 \mathrm{mg} / \mathrm{kg}$ showed significant reduction in the levels of IL $1 \beta(p<0.05)$ and comparable to that of fluoxetine $(\mathrm{p}<0.05)$. Sitagliptin $5 \mathrm{mg} / \mathrm{kg}$ showed a decrease in the trend, however not statistically significant.

\section{IL6}

Sitagliptin $5 \mathrm{mg} / \mathrm{kg}$ and $9 \mathrm{mg} / \mathrm{kg}$ showed reduction in the levels of IL6 in dose dependent manner. However, the results were not statistically significant

\section{TNF alpha}

Sitagliptin $9 \mathrm{mg} / \mathrm{kg} \quad(\mathrm{p}<0.05)$ showed a statistically significant reduction in the levels of $\mathrm{TNF} \alpha$ and were comparable to that of fluoxetine $(\mathrm{p}<0.05)$. Sitagliptin 5 
$\mathrm{mg} / \mathrm{kg}$ showed a decrease in the trend, however not statistically significant.

Oxidative stress is the imbalance between the oxidative and antioxidative systems and has been implicated in the pathophysiology of several neuropsychiatric diseases, including MDD. ${ }^{18}$ It has been confirmed by numerous studies that depressive patients are characterized by activation of immune and inflammatory response systems, both in the periphery and in the central nervous system. Activation of immune and inflammatory response favours production of reactive oxygen species (ROS) by various mechanisms. ${ }^{19}$ Considering the potential presence of processes and factors which can stimulate the production of ROS in depressive patients and cause alterations of the pro and antioxidative equilibrium, it was aimed to assess changes in the activity of antioxidative enzymes - catalase (CAT), reduced GSH and NO. Plasma samples were collected for estimation of the oxidative stress markers.

\section{Catalase}

Sitagliptin $5 \mathrm{mg} / \mathrm{kg}$, sitagliptin $9 \mathrm{mg} / \mathrm{kg}$ and fluoxetine 2.7 $\mathrm{mg} / \mathrm{kg}$ did not show any statistically significant results. This is consistent with the findings of Galecki et al, used $20 \mathrm{mg}$ of fluoxetine which did not influence the activities of SOD1 and CAT and did not modify pro-oxidative processes or antioxidative systems. ${ }^{20}$

\section{Nitric oxide}

Sitagliptin $9 \mathrm{mg} / \mathrm{kg}$ showed a statistically significant reduction in the levels of NO $(p<0.05)$. These results were comparable with that of fluoxetine $(\mathrm{p}<0.05)$. Sitagliptin 5 $\mathrm{mg} / \mathrm{kg}$ showed a decrease in trend but did not show statistically significant results.

\section{Reduced GSH}

Although both the test drugs and fluoxetine showed an increase in trend in the levels of GSH, they were not statistically significant. This finding was consistent with the studies performed by Galecki et al who did not find significantly different level of GPX in depressed patients. $^{21}$

Thus, our study showed that sitagliptin could alleviate depressive symptoms in male wistar rats using Forced Swim test. Based on the results obtained, there appears to be a role of DPP-4 inhibitors in depression, most probably by their anti-inflammatory and anti-oxidative properties. More and more research is required to substantiate and elucidate the role of DPP-4 inhibitors in behavioural disorders like depression. Hence, there is a strong need to take up these drugs for further evaluation through well planned clinical trials.

\section{Funding: No funding sources} Conflict of interest: None declared

Ethical approval: The study was approved by the Institutional Ethics Committee

\section{REFERENCES}

1. Andrade L, Caraveo A, Berglund J. The Epidemiology of Major Depressive Episodes: Results from the International Consortium of Psychiatric Epidemiology (ICPE) Surveys. Int J Methods Psychiatr. 2003;2:3-21.

2. Pattanayak R, Sagar R. Depressive Disorders in Indian Context- A Review and Clinical Update for Physicians. J Assoc Physians India. 2014;62:827.

3. Cerdá M, Sagdeo A, Galea S. Comorbid forms of psychopathology: key patterns and future research directions. Epidemiol Rev. 2008;30:155-77.

4. Fava M, Davidson KG. Definition and epidemiology of treatment-resistant depression. Psychiatr Clin North Am. 1996;19(2):179-200.

5. Zorilla P, Lubosky L, Rosenthal R, Houldin A, McKay JR. The Relationship of Depressor and Stressors to Immunological Assays. Brain Behav Immun. 2001;15:199-226.

6. Castagné V, Moser P, Porsolt RD. Behavioral Assessment of Antidepressant Activity in Rodents. In: Buccafusco JJ, editor. Methods of Behavior Analysis in Neuroscience. 2nd edition. Boca Raton (FL): CRC Press; 2009.

7. Ellman GL. Determination of sulfhydryl group. Arch. Biochem. Biophys. 1959;82:70-4.

8. Green LC, Wagner DA, Glogowski J, Skipper PL, Wishnok JS, Tannenbaum SR. Analysis of nitrate, nitrite and $[\mathrm{N}]$ nitrate in biological fluids. Anal Biochem. 1982;126:131-8.

9. Goth L. A simple method for determination of serum catalase activity and revision of reference range. Clin Chim Acta. 1991;196:143-51.

10. Peinnequin A, Mouret C, Birot O, Alonso A, Mathieu J, Clarencon D, et al. Rat pro-inflammatory cytokine related mRNA quantification by real time polymerase chain reaction using SYBR green. BMC Immunol. 2004;5(1):3.

11. De Muth JE. Basic statistics and pharmaceutical statiscal applications. 2nd ed. Boca Raton(FL): Chapman and Hall/CRC Press; Chapter 11. Multiple comparison tests: 2006: 229-266.

12. Kamble M, Gupta R, Rehan H, Gupta L. Neurobehavioral effects of liraglutide and sitagliptin in experimental models. European J Pharmacol. 2016;774:64-70.

13. Marques C, Mega C, Gonçalves A, Rodrigues-Santos P, Teixeira-Lemos E, Teixeira F, et al. Sitagliptin Prevents Inflammation and Apoptotic Cell Death in the Kidney of Type 2 Diabetic Animals. Mediators of Inflammation. 2014;2014:1-15.

14. El-Sahar A, Safar M, Zaki H, Attia A, Ain-Shoka A. Sitagliptin attenuates transient cerebral ischemia/reperfusion injury in diabetic rats: Implication of the oxidative-inflammatory-apoptotic pathway. Life Sci. 2015;126:81-6.

15. Tsao CW, Lin YS, Chen CC, Bai CH, Wu SR. Cytokines and serotonin transporter in patients with 
major depression. Prog Neuropsychopharmacol Biol Psychiatry. 2006;30:899-905.

16. Cattaneo A, Gennarelli M, Uher R, Breen G, Farmer A, Aitchison KJ, et al. Candidate genes expression profile associated with antidepressants response in the GENDEP study: differentiating between baseline 'predictors' and longitudinal 'targets'. NeuropsychoPharmacol. 2013;38:377-85.

17. Felger J, Lotrich F. Inflammatory cytokines in depression: Neurobiological mechanisms and therapeutic implications. Neurosci. 2013;246:199229.

18. Sarandol A, Sarandol E, Eker S, Erdinc S, Vatansever E, Kirli S. Major depressive disorder is accompanied with oxidative stress: short-term antidepressant treatment does not alter oxidativeantioxidative systems. Human Psychopharmacol Clin Experimental. 2007;22(2):67-73.

19. Gałecki P, Szemraj J, Bieńkiewicz M, Zboralski K, Gałecka E. Oxidative stress parameters after combined fluoxetine and acetylsalicylic acid therapy in depressive patients. Human Psychopharmacol Clinical and Experimental. 2009;24(4):277-86.

20. Galecki P, Kêdziora J, Florkowski A, Galecka E. Lipid peroxidation and Copper-Zinc Superoxide Dismutase activity in patients treated with fluoxetine during the first episode of depression (Polish). Psychiatria Polska. 2007;41:615-24.

21. Lukic I, Mitic M, Djordjevic J, Tatalovic N, Bozovic N, Soldatovic I, et al. Lymphocyte Levels of RedoxSensitive Transcription Factors and Antioxidative Enzymes as Indicators of Pro-Oxidative State in Depressive Patients. Neuropsychobiol. 2014;70(1):1-9.

Cite this article as: Mahalmani VM, Hogade AP, Mishra SK. Effect of sitagliptin on depression in male wistar rats. Int J Basic Clin Pharmacol 2020;9:200-6. 